\title{
Symptoms of Respiratory Disease and Lung Functional Impairment Associated with Occupational Inhalation Exposure to Carbon Black Dust
}

\author{
Masoud Neghab ${ }^{1}$, Majid Habibi Mohraz ${ }^{1}$ and Jafar HassanZadeH ${ }^{2}$ \\ ${ }^{1}$ Department of Occupational Health, School of Health and Nutrition and Research Center for Health Sciences and \\ ${ }^{2}$ Department of Epidemiology, School of Health and Nutrition, Shiraz University of Medical Sciences, Iran
}

\begin{abstract}
Symptoms of Respiratory Disease and Lung Functional Impairment Associated with Occupational Inhalation Exposure to Carbon Black Dust: Masoud NeghaB, et al. Department of Occupational Health, School of Health and Nutrition and Research Center for Health Sciences, IranPurpose: The aim of this study was to ascertain whether symptoms of respiratory disorders and lung functional impairments are associated with occupational inhalation exposure to carbon black (CB) in a group of rubber workers. Methods: The study population consisted of 72 male workers with a past history of and current exposure to $\mathrm{CB}$ and 69 , randomly selected, healthy unexposed male office workers that served as the referent group. Subjects were interviewed and given standardized respiratory symptom questionnaires to answer. Furthermore, pulmonary function tests (PFTs) were performed before and after the work shift for exposed subjects and once during the work shift for referent subjects. Furthermore, to assess the extent to which workers were exposed to $\mathrm{CB}$, using standard methods, inhalable and respirable dust fractions of $C B$ were measured in different dusty worksites. Results: The levels of exposure to inhalable and respirable $C B$ dust were estimated to be $6.2 \pm 1.7$ and $2.3 \pm 0.29 \mathrm{mg} /$ $\mathrm{m}^{3}$ respectively (mean $\pm \mathrm{SD}$ ). Respiratory symptom questionnaires revealed that regular cough, phlegm, wheezing and shortness of breath were significantly $(p<0.05)$ more prevalent among exposed workers. Furthermore, significant decreases in some preshift and postshift parameters of pulmonary function of exposed workers with a spirometric pattern consistent with restrictive ventilatory disorder were found. Conclusion: The findings of this study provide circumstantial evidence to support the notion that exposure to $C B$
\end{abstract}

Received Apr 17, 2011; Accepted Sep 15, 2011

Published online in J-STAGE Oct 13, 2011

Correspondence to: M. Neghab, P.O Box 111, Postcode 71645,

Shiraz,Iran(e-mail:neghabm@sums.ac.ir) exceeding its current TLV is associated with a significant increase in the prevalence of respiratory symptoms along with both acute, partially reversible and chronic irreversible significant decreases in some parameters of pulmonary function.

(J Occup Health 2011; 53: 432-438)

Key words: Carbon black, Respiratory symptoms, Rubber industry, Ventilatory disorders

Carbon black is the powder form of elemental carbon manufactured by the controlled vapor-phase pyrolysis of hydrocarbons ${ }^{1)}$. Carbon black, unlike diamond and graphite, which are crystalline carbon, is a form of amorphous carbon that has a high surface area to volume ratio $^{2)}$. The oil furnace process produces nearly all the world's carbon black, which is used in the manufacture of tires, retread rubber and inner tubes ${ }^{3,4}$. According to International Carbon Black Association reports, the total production of carbon black was around 8,100,000 metric tons in 2006 ${ }^{5}$.

While material mixing and warehouse workers of tire production industries are probably a main group of carbon black-exposed workers and there are many concerns about the adverse effects of permanent exposure to this substance, the possible effect (s) of this chemical exposure on pulmonary function has not been thoroughly investigated and is subject to debate and controversy.

For instance, while some studies ${ }^{3,6-8)}$ have shown inhalation exposure to this powder to be associated with chronic bronchitis, symptoms such as cough and phlegm as well as impaired lung function and ventilatory disorders marked by significant decrements in FVC and FEV1, others $^{9-13)}$ have failed to detect such associations.

Gardiner et al. showed that carbon black has deleterious effects on the respiratory system and that the symptoms of these effects include productive cough, phlegm and decrements in some of pulmonary functions such as FEV1, 
FEF25-75\% and the FEV1/FVC ratio $^{3)}$.

In contrast, Robertson et al. showed that there is no association between occupational exposure to this substance and changes in pulmonary functions and that observed decrements in FEV1 and FVC were strongly influenced by age and smoking ${ }^{11)}$.

Additionally, a comprehensive review article has concluded that the majority of carbon black studies have methodological drawbacks such as the validity of the techniques used for health assessment, a limited study population, incorrect subject selection criteria, lack of proper control for confounding variables (smoking, previous exposures etc.) and cross-exposure with other chemicals such as carbon monoxide, vapors, etc. ${ }^{14}$.

Therefore, the main purpose of this study was to assess and characterize, after proper control of confounding variables, the pulmonary reactions, if any, associated with occupational inhalation exposure to carbon black among a group of rubber workers.

\section{Materials and Methods}

\section{Subjects and study design}

This cross-sectional study was carried out at a local rubber factory in Shiraz, Iran. The plant has been producing tires, tubes and flaps since 1935 and currently has 1,800 staff.

The production process begins with the mixing of basic kinds of rubber with process oils, carbon black, pigments, antioxidants, accelerators and other additives, and each of these hazardous chemicals contributes certain properties to what is called a compound. These ingredients are mixed in giant blenders called Banburies. They blend the many ingredients together, producing a black, gum-like material that will be milled again later for use in production of tires.

A total of 72 workers with a past history of and current exposure to $\mathrm{CB}$ were studied. They were from three job categories including $\mathrm{CB}$ warehouse, loading and Banbury workers.

A Banbury mixer is a closed mixing machine in which materials are mixed together in a properly closed chamber.

In this factory, raw materials such as sulfur, pigments, antioxidants, accelerators, etc. are weighed in an isolated area, equipped with a local exhaust ventilation system outside the Banbury section. Thereafter, they are transported to the Banbury by closed container and injected into the Banbury mixer. Moreover, process oils are injected automatically by the Banbury device into enclosed mixing chambers. Thus, exposure of workers to these materials in the Banbury section could be considered negligible.

In contrast, carbon black is transferred to mixing devices by a semiclosed conveyer from four reservoirs located in the upper part of the Banbury. Due to improper maintenance of the $\mathrm{CB}$ transportation system, significant leakage of $\mathrm{CB}$ from the semiclosed conveyers and the direct connection between the $\mathrm{CB}$ loading section and Banbury, the workplace environment is heavily contaminated with this chemical. The situation in previous years was even worse, as $\mathrm{CB}$ used to be transported by an entirely open system allowing $\mathrm{CB}$ particles to be easily dispersed in the workplace. Given the above and the fact that the workers in the carbon black loading and warehouse sections, who were not wearing any respiratory protective devices, were only exposed to carbon black dust, it is expected that the studied subjects are a homogeneous group in terms of their dermal and inhalation exposure to this substance.

Similarly, 69 healthy unexposed subjects were randomly selected from the plant and served as the referent group. The study was conducted in accordance with the Helsinki Declaration of 1964 as revised in 2007 ${ }^{15)}$.

Both the exposed and unexposed subjects were volunteers. No subject refused to participate in the study. All participants signed an informed consent form before commencement of the study.

\section{Measurement of study variables}

1) Respiratory illness

Subjects were interviewed, and a respiratory symptom questionnaire, as suggested by the American Thoracic Society ${ }^{16)}$, with a few modifications, was administrated to them at the end of the work shift. This standardized questionnaire included questions regarding respiratory symptoms (presence or absence of regular dry and/or productive cough, wheezing, shortness of breath, etc.), nasal and eye symptoms and smoking habits, as well as the occupational, medical and family history of each subject.

Symptoms of chronic respiratory disorders were defined as a cough with sputum at any time during the day or night for at least three months of the year and for at least two consecutive years.

Information extracted from the questionnaires was then used to obtain symptom prevalence data among the exposed and unexposed groups.

2) Pulmonary function tests

Pulmonary function tests (PFTs) were performed using a portable calibrated vitalograph spirometer (vitalograph, COMPACT, Buckingham, England) on-site, twice for the exposed workers (before commencing work and at the end of the work shift) and once for the referent subjects. The measured parameters included mean percentage predicted vital capacity (VC), forced vital capacity (FVC), forced expiratory volume (FEV1) and peak expiratory flow (PEF). Spirometer calibration was conducted twice a day with a 1-liter syringe in accordance with the spirometer manufacturer's standard protocol. The mean percentage predicted values were based on subject age, weight, 
standing height, sex and ethnic background as calculated and adjusted by the spirometer device ${ }^{17)}$.

Subjects were trained to become familiar with the maneuver and were requested not to take shower or smoke for at least two hours prior to the test.

The weight and standing height of each individual was measured with their usual work clothes. Before the test, they rested in a sitting position for about $5 \mathrm{~min}$. They were then asked to stand in front of the spirometer, as comfortably as possible, and a nose clip was put on. At least three acceptable tests were obtained for each subject. If the variability between the measured values was high, the tests were performed up to five times. The largest volumes (as percentage predicted lung function) were selected for analysis. The percentage predicted lung values were observed capacities as measured by the spirometer device divided by predicted or expected capacities (based on gender, age, weight, height, ethnic background, etc., as calculated and adjusted by the spirometer device) and multiplied by 100 .

$\%$ predicted lung value $=($ observed capacities $/$ expected capacities) $\times 100$.

\section{Measurement of atmospheric concentrations of $C B$}

To assess the extent to which workers were exposed to CB using the NIOSH method ${ }^{18)}$, atmospheric concentrations (respirable and inhalable dust fractions) of it were determined in three work areas, and the mean concentration was expressed in $\mathrm{mg} / \mathrm{m}^{3}$. Air samples were collected using SKC personal air sampling pumps equipped with a cyclone and a Millipore PVC membrane filter ( $5 \mu \mathrm{m}$ pores) in order to separate respirable and inhalable fractions of CB dust. Pretest experiments showed that the appropriate sampling time was about $180 \mathrm{~min}$.

\section{Data analysis and statistical procedures}

The data were statistically analyzed using the Student's $t$-test, chi-square or Fisher's exact test and logistic and multiple linear regression analysis, where applicable. In all the statistical comparisons, a $p$ value of less than 0.05 was considered significant. Experimental (descriptive) results are presented as arithmetic means \pm SD. To conduct the logistic and multiple linear regression analysis, the main exposure variable was considered to be carbon black dust. Other variables such as age, weight, height, smoking habits, education, and marital status were considered as potential confounders, and their simultaneous effects on the prevalence of respiratory symptoms and changes in the parameters of pulmonary function were controlled. The initial model was constructed based on the main exposure variable (carbon black) as well as all potential confounding variables. Using the backward elimination method and keeping the main exposure variable, carbon black, in the model, the final model was obtained. Statistical tests were conducted using SPSS V16.0 on a personal computer.

\section{Results}

The average (mean \pm SD) age (yr), weight $(\mathrm{kg})$, height (cm), duration of exposure (length of employment for referent subjects), length (yr) and severity of smoking and airborne concentrations of CB are presented in Table 1.

As shown, the referent subjects were to some extent older than their exposed counterparts, and the difference was statistically significant. Additionally, the mean atmospheric concentration of $\mathrm{CB}$ was higher than the current TLV value of $3.5 \mathrm{mg} / \mathrm{m}^{3,18)}$.

Unfortunately, there was not any information available concerning the exposure scenarios before we undertook the current study. However, in the absence of local exhaust ventilation systems and given the lack of proper housekeeping programs and the workers' reluctance to wear their masks, the subjects were likely to be exposed to similar concentrations, if not higher, of $\mathrm{CB}$ dusts in previous years.

Table 2 shows the frequency of abnormal respiratory findings. As shown, the prevalence of regular cough, phlegm, wheezing and breathlessness were significantly higher in exposed subjects compared with in the referent subjects $(p<0.0005)$.

None of the exposed subjects had a past medical or family history of respiratory illness or any other chest operations or injuries. Likewise, none of the referent subjects had been exposed to $\mathrm{CB}$ or other chemicals known to cause respiratory symptoms or ventilatory disorders during employment at the plant or prior to it.

Table 3 illustrates the results of lung function tests. As shown, exposure to $\mathrm{CB}$ was associated with a significant reduction in VC, FVC, FEV1, FEV1/FVC and PEF parameters after exposure when compared with the values measured before exposure. Similarly, most parameters of pulmonary function of exposed individuals both before and after exposure were significantly lower than those of unexposed individuals.

The association between exposure to $C B$ and the prevalence of respiratory symptoms is displayed in Table 4. Logistic linear regression analysis including variables of age, weight, height, smoking habit, education and marital status in the model showed that after adjusting for these important confounders, there was a statistically significant association between exposure to $\mathrm{CB}$ and respiratory symptoms.

Similarly, the association between exposure to $\mathrm{CB}$ and changes in the parameters of pulmonary function is shown in Table 5. Multiple linear regression analysis, including variables of age, weight, height, smoking habit, education and marital status in the model showed that after adjusting for these important confounders, there was a statistically significant association between exposure to $\mathrm{CB}$ and $\mathrm{VC}$, FVC, FEV1 and the FEV1/FVC ratio, with exposure to 
Table 1. Comparison of demographic variables, smoking habits and level of exposure of studied subjects to carbon black

\begin{tabular}{|c|c|c|c|}
\hline Variable & Exposed $(\mathrm{n}=72)$ & Referent ( $\mathrm{n}=69)$ & $p$ value \\
\hline Age (yr) $(\mathrm{X} \pm \mathrm{SD})$ & $32.7 \pm 5.97 *$ & $35.6 \pm 9.64$ & 0.03 \\
\hline Weight $(\mathrm{kg})(\mathrm{X} \pm \mathrm{SD})$ & $75.6 \pm 12.58$ & $77.9 \pm 11.14$ & 0.26 \\
\hline Height $(\mathrm{cm})(\mathrm{X} \pm \mathrm{SD})$ & $173.6 \pm 8.3$ & $176.6 \pm 7$ & 0.26 \\
\hline $\begin{array}{l}\text { Length of exposure/ } \\
\text { employment (yr) }(\mathrm{X} \pm \mathrm{SD})\end{array}$ & $9.04 \pm 4.93$ & $10.41 \pm 8.2$ & 0.23 \\
\hline No. $(\%)$ smokers & $20(27.8)$ & $15(21.7)$ & 0.5256 \\
\hline $\begin{array}{l}\text { Length of smoking }(\mathrm{yr}) \\
(\mathrm{X} \pm \mathrm{SD})\end{array}$ & $3.16 \pm 6.3$ & $3.73 \pm 8.34$ & 0.32 \\
\hline $\begin{array}{l}\text { Number of cigarettes } \\
\text { smoked per day }(X \pm S D)\end{array}$ & $2.58 \pm 5.43$ & $3.18 \pm 9.58$ & 0.32 \\
\hline $\begin{array}{l}\text { Inhalable concentration of carbon } \\
\text { black }\left(\mathrm{mg} / \mathrm{m}^{3}\right)(\mathrm{X} \pm \mathrm{SD})^{\dagger}\end{array}$ & $6.2 \pm 1.7$ & N/A & N/A \\
\hline $\begin{array}{l}\text { Respirable concentration of carbon } \\
\text { black }\left(\mathrm{mg} / \mathrm{m}^{3}\right)(\mathrm{X} \pm \mathrm{SD})^{\dagger}\end{array}$ & $2.3 \pm 0.29$ & N/A & N/A \\
\hline
\end{tabular}

* Significantly different from its corresponding value in the referent group. ${ }^{\dagger}$ Chi-square or Fisher's exact test or independent $t$-test, $p<0.05$. N/A: Not Applicable. Number of air samples=6.

Table 2. Frequency (\%) of respiratory symptoms among exposed and nonexposed subjects

\begin{tabular}{lccc}
\hline Symptoms & Exposed $(\mathrm{n}=72)$ & Nonexposed $(\mathrm{n}=69)$ & $p$ value $^{\dagger}$ \\
\hline Cough & $23.6^{*}$ & 1.44 & 0.0001 \\
Phlegm & $41.66^{*}$ & 5.79 & 0.0001 \\
Productive cough & $25^{*}$ & 2.89 & 0.0001 \\
Wheezing & $25^{*}$ & 1.44 & 0.0001 \\
Dyspnea & $31.9^{*}$ & 0 & 0.0001 \\
\hline
\end{tabular}

Chi-square or Fisher's exact test. * Significantly different from its corresponding value for in the nonexposed group.

$\mathrm{CB}$ resulting in an average of 4 to 9 units of decrement in these parameters.

\section{Discussion}

The aim of this study was to evaluate possible pulmonary reactions associated with occupational inhalation exposure to $\mathrm{CB}$.

Given the data provided, apart from age, there were no significant differences in the major confounding variables of weight, height, length of employment, number of smokers, length of smoking and severity of smoking between the exposed and unexposed groups.

Interestingly, despite the fact that the subjects in the unexposed group were, on average, three years older than their exposed counterparts, the prevalence of respiratory symptoms as well as decrement in parameters of pulmonary function in the exposed group were significantly higher than in the unexposed group. Similar observations have been made by others ${ }^{3,6-8,19-21)}$.

Additionally, as there were no significant differences between the number of smokers and years smoked in both groups, it is unlikely that cigarette smoking accounts for a significantly higher prevalence of respiratory symptoms among the exposed subjects. This conclusion is further supported by the results presented in Table 4, which show that when the effects of potential confounders of age, weight, height, smoking habits, education and marital status in the binary logistic regression analysis were controlled, significant associations were present between exposure to $\mathrm{CB}$ and the prevalence of respiratory symptoms.

Measurement of lung function before and after a 
Table 3. Percentage predicted lung function among exposed and nonexposed subjects

\begin{tabular}{|c|c|c|c|c|c|c|}
\hline \multirow[t]{2}{*}{ Parameters } & \multicolumn{2}{|c|}{$\begin{array}{c}\text { Exposed } \\
(n=72)\end{array}$} & \multirow[t]{2}{*}{$\begin{array}{l}\text { Nonexposed } \\
\quad(n=69)\end{array}$} & \multirow{2}{*}{$\begin{array}{l}p \text { value } \\
\text { Preshift vs. } \\
\text { postshift }\end{array}$} & \multirow{2}{*}{$\begin{array}{c}p \text { value } \\
\text { Preshift vs. } \\
\text { non-exposed }\end{array}$} & \multirow{2}{*}{$\begin{array}{c}p \text { value } \\
\text { Postshift vs. } \\
\text { non-exposed }\end{array}$} \\
\hline & Preshift & Postshift & & & & \\
\hline $\mathrm{VC}$ & $77.76 \pm 13.29^{\dagger}$ & $73.97 \pm 11.97 * \dagger \dagger$ & $82.84 \pm 10.18$ & 0.0002 & 0.0059 & 0.0001 \\
\hline FVC & $75.7 \pm 16.09^{\dagger}$ & $71.86 \pm 12.95^{* \dagger \dagger}$ & $80.89 \pm 10.5$ & 0.0017 & 0.0123 & 0.0001 \\
\hline FEV1 & $76.13 \pm 16.3^{\dagger}$ & $72.25 \pm 14.98 * \dagger$ & $82.73 \pm 13.71$ & 0.0029 & 0.0044 & 0.0001 \\
\hline FEV1/FVC & $100.81 \pm 9.34$ & $98.3 \pm 12.33 *+\dagger$ & $101.92 \pm 9.71$ & 0.005 & 0.2455 & 0.0271 \\
\hline PEF & $75.97 \pm 15.96$ & $69.66 \pm 20.57 *$ & $73.31 \pm 23.34$ & 0.0005 & 0.233 & 0.153 \\
\hline
\end{tabular}

*Significantly different from preshift values (paired $t$-test, $p<0.05$ ). ${ }^{\dagger}, \uparrow$ Significantly different from nonexposed values (independent $t$-test, $p<0.05)$.

Table 4. Association between exposure to carbon black and prevalence of respiratory symptoms

\begin{tabular}{lccc}
\hline Outcome & $\beta$ & Odds ratio & $p$ value \\
\hline Wheezing & 3.314 & 27.49 & 0.002 \\
Productive cough & 2.258 & 9.565 & 0.004 \\
Cough & 2.846 & 17.22 & 0.007 \\
Phlegm & 2.452 & 11.607 & 0.0001 \\
\hline
\end{tabular}

Binary logistic regression. $\beta$ : Odds ratio.

Table 5. Association between exposure to carbon black and changes in the parameters of pulmonary function

\begin{tabular}{lccc}
\hline Parameter & B & SE & $p$ value $^{\dagger \dagger}$ \\
\hline VC & -8.868 & 1.817 & 0.0001 \\
FVC & -9.037 & 1.991 & 0.0001 \\
FEV1 & -8.952 & 2.373 & 0.0001 \\
FEV1/FVC & -4.129 & 1.89 & 0.031 \\
PEF & -4.51 & 3.729 & 0.229 \\
\hline
\end{tabular}

${ }^{\dagger}$ Multiple linear regression model. B: Average units of decrement in each parameter of pulmonary function of exposed subjects compared to their unexposed counterparts. SE: Standard error.

working shift forms the basis of testing for acute, partially reversible and chronic irreversible effects of $\mathrm{CB}$.

To the best of authors' knowledge, the distinction between possible acute and chronic respiratory effects of exposure to $\mathrm{CB}$ in comparison with an appropriate referent group has not been examined by others. In the present study, in order to differentiate between these effects, the parameters of pulmonary functions were measured before and after exposure to $\mathrm{CB}$, and the results were compared within the exposed group and with those of the referent group. As shown in Table 3, there were statistically significant differences in most parameters of pulmonary function before and after exposure. These differences cannot be attributed to circadian variation because the circadian rhythm causes variations in the opposite direction $^{22,23)}$. These results are thought to support the hypothesis that there are acute adverse effects of exposure over the course of a work shift. Therefore, the acute reversible changes in PFTs after a single work shift could be attributed to $\mathrm{CB}$ exposure.

Similarly, when the results of pulmonary function tests of exposed subjects were compared with those of the referent group, significant differences were noted. However, the differences were more pronounced when the values for after exposure were compared with those of the referent subjects. These findings indicate that exposure to $\mathrm{CB}$ is associated with acute, partially reversible and chronic irreversible ventilatory disorders.

These conclusions are also further supported by the results displayed in Table 5, which show that after adjusting for important confounders, including age, weight, height, smoking habit, education and marital 
status, in the multiple linear regression analysis, significant associations were present between decrements in most parameters of pulmonary function and exposure to $\mathrm{CB}$.

The nature of pulmonary disorder associated with exposure to $\mathrm{CB}$ deserves comment. The spirometric pattern of ventilatory disorders found in our study is compatible with those of restrictive pulmonary impairment. Because FVC is reduced in restrictive pulmonary disorders, but the expiratory flow rate, usually measured by FEV1, is normal or reduced proportionately, the ratio of FEV1/FVC is nearly near normal ${ }^{24)}$.

These findings are in line with the observations of Gardiner et $a l^{6}$.

A study of European CB workers also reported that there is a significant association between occupational exposure to $\mathrm{CB}$ and irreversible decrements in some parameters of pulmonary function such as FEV1, FEF25-75\% and the FEV1/FVC ratio ${ }^{3)}$. Similarly, Robertson et al. showed that there was an inverse relationship between forced vital capacity (FVC), forced expiratory volume in 1 second (FEV1) and exposure to CB dust. However, when confounding variables such as age and smoking were controlled, the noted relationship vanished, and the authors concluded that occupational exposure to $\mathrm{CB}$ dust was not associated with decrement in pulmonary function parameters ${ }^{11}$. Similar findings have been reported by Crosbie et al., who revealed using multiple regression analysis that the observed decrements in the pulmonary function parameters of CB-exposed workers were related to the effects of smoking and age ${ }^{13)}$.

Our findings are qualitatively similar to two other studies that had been conducted in tire manufacturing factories by Oleru et al. and Peters et al. In these studies, comparison of CB-exposed workers with unexposed groups showed significant decreases in some of pulmonary function parameters ${ }^{19,20)}$. Interestingly, the workers' exposure to respirable $\mathrm{CB}$ dust in the present study was similar to that in the study of Peters et al.

A cause and effect relationship cannot be established from cross-sectional studies, such as the present study. Therefore, due to this inherent limitation, one might argue that the respiratory symptoms and lung functional impairments observed in this study may not necessarily be causally linked with carbon black exposure. While true, a few lines of evidence indicate that these outcomes are very likely to be the results of exposure to carbon black.

First, the exposed subjects, when employed, were free from any preexisting medical conditions, particularly those involving respiratory symptoms.

Second, apart from carbon black, the exposed individuals had no history of exposure to other chemicals known to cause respiratory disorders prior to their employment in the plant or during the course of their employment, thereafter.
Third, despite the fact that the unexposed subjects were significantly older (on average $3 \mathrm{yr}$ ) than their exposed counterparts, respiratory symptoms and reduced ventilatory capacities were significantly more prevalent in the exposed subjects than in the referent subjects. Additionally, given the fact that, apart from age, the distribution of the confounding variables was similar in both the exposed and unexposed groups (the reason why none of the confounders remained in the final model), one would expect that the effect of age would underestimate the difference noted between the groups.

Fourth, although the exposed subjects performed significantly better in their spirometry test when their exposure to $\mathrm{CB}$ ceased, the differences between the exposed and unexposed subjects for most parameters of pulmonary function remained significant (Table 3). Based on this observation, one might tentatively conclude that the ventilatory disorders noted in this study consist of acute, partially reversible, and chronic irreversible impairments.

\section{Conclusions}

In conclusion, the findings of this study provide circumstantial evidence to support the notion that exposure to $\mathrm{CB}$ exceeding its current TLV is associated with significantly increased prevalence of respiratory symptoms as well as both acute, partially reversible and chronic irreversible significant decreases in some parameters of pulmonary function, with a spirometric pattern consistent with restrictive ventilatory disorders. Therefore, engineering control measures such as local exhaust ventilation and the use of appropriate respirators are recommended to eliminate or reduce workers' exposure to $\mathrm{CB}$ to protect them from developing more severe respiratory diseases in the future.

Acknowledgments: Funding through Shiraz University of Medical Sciences, Vice Chancellor for Research Affairs, partially supported these investigations. The authors also wish to sincerely thank Mr. Ojagh, Mr.Sarvestani and Mrs. Shafieian for their skilful technical assistance in air sampling and completion of questionnaires.

\section{References}

1) Van Tongeren M, Kromhout H, Gardiner K. Trends in levels of inhalable dust exposure, exceedance and overexposure in the European carbon black manufacturing industry. Ann Occup Hyg 2000; 44: 271-80.

2) Printing Processes and Printing Inks, Carbon Black and Some Nitro Compounds. In IARC monographs on the evaluation of carcinogenic risks to humans. Lyon (France): International Agency for Research on Cancer, World Health Organization; 1996. p.1-578.

3) Gardiner K, Van Tongeren M, Harrington M. Respiratory health effects from exposure to carbon black: results of 
the phase 2 and 3 cross sectional studies in the European carbon black manufacturing industry. Occup Environ Med 2001; 58: 496-503.

4) Gardiner K, Calvert IA, Van Tongeren MJA, Harrington JM. Occupational exposure to carbon black in its manufacture: data from 1987 to 1992. Ann Occup Hyg 1996; 40: 65-77.

5) International Carbon Black Association (ICBA). What is Carbon Black. [Online]. 2009 [cited 2011 Mar 5]; Available from: URL: http://www.carbon-black.org/ what_is.html

6) Gardiner K, Trethowan NW, Harrington JM, Rossiter CE, Calvert IA. Respiratory health effects of carbon black: a survey of European carbon black workers. $\mathrm{Br}$ Med J 1993; 50: 1082-96.

7) Gardiner K. Effects on respiratory morbidity of occupational exposure to carbon black: a review. Arch Environ Health 1995; 50: 44-60.

8) Harber P, Muranko H, Solis S, Torossian A, Merz B. Effect of carbon black exposure on respiratory function and symptoms. J Occup Environ Med 2003; 45: 144 55 .

9) Küpper HU, Breitstadt R, Ulmer WT. Effects on the lung function of exposure to carbon black dust: results of a study carried out on 677 members of staff of the DEGUSSA factory in Kalscheuren/Germany. Int Arch Occup Environ Health 1996; 68: 478-83.

10) Robertson JM, editor. Epidemiologic studies in North American carbon black workers. Inhal Toxicol 1996; 8: 41-50.

11) Robertson JMD, Diaz JF, Fyfe IM, Ingalls TH. A crosssectional study of pulmonary function in carbon black workers in the United States. Am Ind Hyg Assoc J 1988; 49: 161-6.

12) Vali F, Beriti -Stahuljak D, Mark B. A follow-up study of functional and radiological lung changes in carbonblack exposure. Int Arch Occup Environ Health 1975; 34: 51-63.
13) Crosbie WA. Respiratory health of carbon black workers. Arch Environ Health 1986; 41: 346-53.

14) Gardiner K. The methodological problems of multinational epidemiological studies with particular reference to carbon black studies. Occup Med 1995; 45: 247.

15) Goodyear MDE, Krleza-Jeric K, Lemmens T. The Declaration of Helsinki. Br Med J 2007; 335: 624-5.

16) Ferris BG. Epidemiology Standardization Project (American Thoracic Society). Am Rev Respir Dis 1978; 118: 1-120.

17) Hnizdo E, Churchyard G, Dowdeswel R. Lung function prediction equations derived from healthy South African gold miners. Occup Environ Med 2000; 57: 698-705.

18) Eller PM, Cassinelli ME. NIOSH manual of analytical methods. 4th edition. Vol 2. Cincinati $(\mathrm{OH})$ : DIANE Publishing; 1994. p.349-53.

19) Oleru UG, Elegbeleye OO, Enu CC, Olumide YM. Pulmonary function and symptoms of Nigerian workers exposed to carbon black in dry cell battery and tire factories. Environ Res 1983; 30: 161-8.

20) Peters JM, Monson RR, Burgess WA, Fine LJ. Occupational disease in the rubber industry. Environ Health Perspect 1976; 17: 31-4.

21) Szozda R. The respiratory health of carbon black workers-differences between Polish, west European and American scientific reports. J UOEH 1994; 16 : 91-5.

22) Guberan MKE, Walford J , Smith MM. Circadian variation of FEV in shift workers. Br J Ind Med 1969; 26: 121-5.

23) Governa M, Comai M, Valentino M, Antonicelli L, Rinaldi F. Ventilatory function in rubber processing workers: acute changes over the workshift. Br J Ind Med 1987; 44: 83-9.

24) Kumar V, Cotran R, Robbin S. Basic Pathology. 6th edition. Philadelphia (PA): WB Saunders Company; 1997. p. 393-425. 